\title{
THE HISTORY OF THE DEVELOPMENT OF NARCOTICS
}

\author{
NATHAN B. EDDY*
}

Man and animals generally seek escape from discomfort. Man today seems more prone to do so than ever before and, as will be seen, has acquired a considerable variety of means to that end. No one knows when man learned that there were natural agents available, the poppy among them, to ease his pains; but he did acquire that knowledge, and there the history of narcotics begins. Legally and otherwise, narcotic has a broader connotation than opiate. Practically, however, the major part of the narcotics problem centers around the opiates and their synthetic substitutes, and this account of historical development will deal with these only.

Chopra suggests that the food value of the seeds of the opium poppy was recognized much earlier than the somniferous property of the capsule or poppy head, ${ }^{1}$ but the capsules were used in the preparation of soporific drugs and soothing beverages from time immemorial. Poppies were grown for the capsules in Asia Minor many centuries ago, and the Arabs carried the dried poppy heads to eastern countries at a very early date. Eventually, someone discovered that at one stage in the development of the poppy plant, Nature seemed to concentrate its soporific properties-that is, the ingredients responsible for them-in the plant juice which would exude from the lanced ripe poppy head. This juice, collected and dried, is crude opium.

Opium became a household remedy and the mainstay of the physician in its crude form, in pills, and in various liquid preparations-laudanum, paregoric, etc.whatever the symptomatic need. It also became a medium of social exchange and self indulgence as a confection and, in modified form, for smoking. Even into the latter half of the nineteenth century, there was little recognition of and less attention paid to overindulgence in or abuse of opium. It was the panacea for all ills. When a person became tolerant to its action and dependent upon it so that abstinence symptoms developed if a dose or two were missed, more was taken for the aches and pains and other discomforts of abstinence, just as it was taken for similar symptoms from any other cause.

In the first decade of the last century, just about $15^{\circ}$ years ago, the curiosity of Sertürner, a German pharmacist, brought about the separation and recognition of

* M.D. I9Ir, Cornell University. Chief, Section on Analgesies, Laboratory of Chemistry, National Institute of Arthritis and Metabolic Diseases, U. S. Department of Health, Education and Welfare; Secretary, Committee on Drug Addiction and Narcotics of the National Research Council; Member, Expert Panel on Drugs Liable to Produce Addiction, World Health Organization; Consultant, World Health Organization. Research Professor of Pharmacology, University of Michigan, 1930-39. Author of many papers on the relation of chemical structure and action of narcotics and synthetic analgesics.

${ }^{1}$ Chopra, Quasi-medical Use of Opium in India and Its Effects, 7 Bull. Narcorics, I (1956). 
the main ingredient of opium. ${ }^{2}$ Sertürner called the agent morphine; but, although it was admittedly the most important active constituent of opium, physicians were slow to use it in preference to the crude drug, and there were many assertions of the superiority of the latter, even after the discovery of the hypodermic syringe towards the middle of the century.

Codeine, another of the natural alkaloids of opium, was isolated only a few years after the discovery of morphine. It was tried almost immediately in clinical medicine $^{3}$ but gained little popularity for about another fifty years. The first artificially produced derivative of morphine appears to have been apomorphine; ${ }^{4}$ ethylmorphine (dionin) was reported in $188 \mathrm{I} ;{ }^{5}$ and in 1890 , Dott and Stockman described a series of morphine derivatives and discussed at length the modifications of action produced by changes in chemical structure. ${ }^{6}$

Up to this time, the principal objective of work in this field was elucidation of the structure of morphine. Attention, however, began to be focused on improvement in therapeutic effectiveness when diacetylmorphine (heroin) was introduced in 1898.7 The frequent abuse of morphine and the phenomena of addiction had begun to be recognized, and heroin was hailed as a drug of increased effectivencss with decreased addiction liability. This was the first of a series of such claims for new agents arising from overenthusiastic misinterpretation of inadequate data, usually advanced in spite of warnings of danger. Even the early literature on heroin contains such warnings. Strube, for example, noted that his patients liked the new drug and continued to take the heroin pills after he ceased to prescribe them; he admitted the possibility of addiction. ${ }^{8}$ Nevertheless, heroin gained rapidly in popularity, became eventually the drug of choice in the illicit drug traffic, and, in some quarters, still is considered indispensable.

The next thirty years saw much work on the morphine structure, intensive investigation of the details of morphine action in the body, but introduction of comparatively few new morphine derivatives. Worth mentioning, however, are dihydrocodeine, dihydromorphine, dihydrocodeinone (dicodid, Hycodan), dihydromorphinone (Dilaudid), and dihydrohydroxycodeinone (eukodal), all of which were tried in Germany during this period. Dilaudid was introduced in this country

${ }^{2}$ See Sertüner, De la morphine et de l'acide méconique, considerés comme parties essentielles de l'opium, 5 ANN. D. CHIM. eT PHYs. 21 (18I7).

${ }^{3}$ See Barbier, Observations sur la codeine considerés comme agent therapestique, 6 BuL.t. GEN. TuERAP. I 41 (1834).

See Matthiesen and Wright, Apomorphia, a New Base Derived from Morphine, in Pharm. J. \& Tr. 23, 40 (1869).

${ }^{5}$ See Grimaux, Sur la transformation de la morphine en codeine et en bases homologues, 92 CoMPT. REND. ACAD. SC. II 40 (I88I).

${ }^{6}$ Dott and Stockman, Pharmacology of Morphine and Its Derivatives, I7 Proc. Roy. Soc'y EpIN. 321 (I890).

${ }^{7}$ See Dreser, Pharmakologisches ïber einige Morphinderivative, 24 DEUT. MEv. WNScHR. 185 (1898); Strube, Mittheilung ïber therapeutische Versuche mit Heroin, 35 BerL. kLIN. WNscim. 903 (1898).

${ }^{8}$ Strube, supra note 7. 
in I932; the use of dicodid for cough began some years later; and interest in dihydrocodeine is currently being revived.

Beginning in 1929 and continuing for about eleven years, the Drug Addiction Committee of the National Research Council directed a comprehensive program of chemical, pharmacological, and clinical investigations, which included the production and testing of about ${ }^{5} 0$ morphine derivatives and twice that number of compounds synthesized from simpler chemical structures. The program had two major accomplishments to its credit: the proof, by accumulation of systematic data, that chemical modification of morphine is not always followed by uniform modification of all of its many effects on the animal body; and the demonstration of significant analgesic (pain-relieving) action with simpler chemical substances not closely related to the structure of morphine. Two of the new morphine derivatives assumed practical importance and were introduced to physicians generally. One of these, metopon, had increased analgesic power, especially when taken by mouth, with less of the dulling effect which morphine has on the senses generally. The other, desomorphine, had greatly increased analgesic power of short duration, with little or no tendency to produce nausea or vomiting so commonly seen when morphine is used. None of the many synthetic substances investigated merited extensive clinical trial, and no morphine-like analgesic without addiction liability was found.

In the late 1930's, German chemists were looking for a synthetic substitute for atropine. One product of this research was shown to have significant analgesic effect and, subsequently, other morphine-like properties; this was meperidine (pethidine, Demoral, Dolantin, etc.)..$^{9}$ Thus, a by-product of one investigation became the first wholly synthetic pain-relieving drug with an activity comparable practically to that of morphine. At first sight, meperidine appeared to bear no relation to the chemical structure of morphine, in spite of similarities of action. After the fact-i.e., after the demonstration of its analgesic effect-however, Schaumann quite ingeniously showed that there were, indeed, chemical features common to the structures of both compounds.

Recognition of the morphine-like characteristics of meperidine, caused it to be brought almost immediately under narcotics control in Germany. At that time, in this country, however, there were no means for bringing about such control of a substance not derived from the natural sources specifically named in the narcotics law, and this lack was corrected only by the enactment of a special statute on July I, 1944. ${ }^{10}$ Meanwhile, although tests at the Public Health Service Addiction Research Center had demonstrated its addiction potentiality, ${ }^{11}$ the impression was fostered that meperidine was relatively safe in this respect. Unfortunately, this false impression persists, and persons have become addicted to meperidine who might have escaped if there had been an understanding of the risk involved. Rasor and Crecraft

${ }^{\circ}$ See Eisleb and Schaumann, Dolantin, ein neuartige Spasmolytikum and Analgetikum (chemisches und pharmakologisches), 65 DEUT. MED. WNscrR. 967 (1939).

${ }_{10} 58$ STAT. 72 I (1944), 2 I U. S. C. $\$$ ITI(a) (1952).

11 See Himmelsbach, Studies of the Addiction Liability of "Demetol" (D-T千0), 75 J. Pharmacol. 64 (1942); Further Studies of the Addiction Liability of Demerol, 79 id. at 5 (1943). 
reported the admission to the Public Health Service Hospital at Lexington of 457 meperidine addicts in a thirty-eight-month period to September $x, 1954 .^{12}$ Nearly half of them were members of the medical or ancillary professions, who, for the most part, admitted that they turned to this drug because they thought it less likely to produce addiction. Confirmed addicts, too, turn to meperidine when it is available; thirty-seven per cent of Rasor's cases had been addicted to other narcotics first. Meperidine is not readily available through illegal sources, but physicians seem less loathe to prescribe it than other narcotics-most probably owing to the impression of relative safety already commented on. The majority of meperidine addicts admitted to Lexington stated that physicians were their source of supply.

Meperidine production in this country was 123,362 ounces in $1946,251,009$ ounces in 1952 , and 394,048 ounces in 1955 . Of the last amount, 329,348 ounces were for domestic use, 20,108 ounces for export. Morphine production was about 100,000 ounces in 1946 and was 49,062 ounces in 1955. Again, these figures seem to reflect the greater readiness of physicians to prescribe meperidine, because if one were to assume that all of the decrease in morphine production was replaced by meperidine, the amount required for such replacement should be only about 250,000 ounces, the dose ratio between the two drugs being of the order of $\mathrm{I}: 5$.

The discovery of meperidine had a greater effect on the over-all narcotic picture than its replacement or potential replacement of morphine. As a replacement, it still has the disadvantages of the latter, but the degree of success as a morphine substitute which it represented had a tremendously stimulating effect on the work of organic chemists in this field. The original German investigators and others there, in England, and in America made many meperidine derivatives, striving, as had been done in the program of the Drug Addiction Committee, to dissociate by chemical modification the features responsible for pain relief from those which produced undesirable side-effects and addiction. A few of these modifications came to clinical trial and some to considerable medical use. Alphaprodine, for example, is reported to be a very useful adjunct to nitrous oxide anesthesia. Ketobemidone is a very powerful pain-relieving drug but develops an intense physical dependence (addiction) with great rapidity; its addiction liability has deterred manufacturers from developing it in this country and has led to a recommendation that its medical use be abolished entirely.

German chemists again achieved an outstanding success in the 1940's by the synthesis of methadone, qualitatively morphine-like in nearly all respects in animals and man and quantitatively equivalent to morphine as a pain-relieving drug, milligram for milligram. ${ }^{13}$ Again, methadone seemed very unlike morphine (or meperidine) in

${ }^{12}$ Rasor and Crecraft, Addiction to Meperidine Hydrochloride (Demerol Hydrochloride), 157 A. M. A. J. 654 (r955).

${ }^{13}$ See Scott and Chen, The Action of $1, r$-diphenyl-r-(dimethylaminoisopropyl)-butanone-2, a Potent Analgesic Agent, 87 J. Pharmacol. 63 (1946); Isbell, et al., Tolerance and Addiction Liability of 6-Dimethylamino-4, 4-diphenyl-heptanone-3 (Methadon), I35 A. M. A. J. 888 (1947); Denton and Beecher, New Analgesics. II. A Clinical Appraisal of the Narcotic Power of Methadone and Its Isomers, I 4 I id. at Ir 46 (r949). 
structure; but again, close scrutiny revealed that there were structural characteristics common to all three. Methadone very easily substituted for morphine in an established addiction, readily produced tolerance and addiction when administered alone, but differed significantly from morphine in the abstinence syndrome which followed abrupt withdrawal of the drug. The methadone abstinence syndrome was slower in onset (two to three days as compared with about twelve hours after morphine), less intense, and much more prolonged.

Methadone is so morphine-like in all of its pharmacological characteristics that it could undoubtedly be used in place of morphine in general medical practice. The only advantage of such use, however, would seem to be the relatively mild, prolonged abstinence syndrome, making withdrawal of the drug easier should addiction develop.

A recent report compared more than 200 methadone derivatives with respect to the effect of chemical modifications on analgesic effectiveness. ${ }^{14}$ Only a few of these have been tried in man, and none has yet come into general use. Work on this group of compounds continues, however, and currently two members of the series give some promise of clinical usefulness.

Through the years, chemists came to a very complete understanding of the chemical constitution of morphine but attained its total synthesis only quite recently. ${ }^{15}$ This is an outstanding scientific achievement, but for the greatest analgesic effectiveness, complete synthesis is not necessary. In 1947, Grewe had already synthesized $\mathrm{N}$-methylmorphinan, representing the basic ring structure of morphine, but without all of its peripheral groups; ${ }^{16}$ and in 1949 , Schnider and Grüssner moved a step closer to morphine by the preparation of 3 -hydroxy- $\mathrm{N}$-methylmorphiman (racemorphan, Dromoran) ${ }^{17}$ They also made the methyl ether-that is, the codeine analog (racemethorphan)-in this new series. Racemorphan is a more powerful analgesic than morphine, with at least as long a duration of action. Like morphine, it is addicting; and like morphine, it is prone to produce the same side-effects, but perhaps somewhat less frequently. Racemorphan and racemethorphan are mixtures of optical isomers, and it has been proven that analgesic action and addiction are produced by one of these isomers only. Most interestingly, the nonaddicting isomer (dextromethorphan) of the codeine analog has been shown to be an effective agent for the relief of cough and is marketed for that purpose.

The chemists have not nearly exhausted the possibilities in any one of the groups of analgesic compounds which have been mentioned-modifications of morphine, meperidine, methadone, or morphinan structures. They have, nevertheless, branched out in other directions and synthesized entirely new structures which have proved to be as potent as morphine in pain-relieving power, at least experimentally-

${ }^{14}$ Braenden, Eddy, and Halbach, Synthetic Substances with Morphine-like Effect. Relationship between Chemical Structure and Analgesic Action, 13 Bull. World Healt7r Org's, 937 (1955).

${ }^{15}$ See Gates and Tschudi, The Synthesis of Morphine, 74 J. AM. CHEM. Soc'y, I Iog (I952); 78 id. at $r_{3} 80$ ( 1956$)$.

${ }^{10}$ See Grewe, Synthetic Drugs with Morphine Action, A 59 ANG. Chem. I94 (1947).

${ }^{17}$ See Schnider and Grüssner, Synthese von Oxy-Morphinanen, 32 Helvet. ChMM. ACTA 821 (I949). 
dithienylbutenylamines, hexamethyleneimines, and phenylcyclohexanes, for example, to name only three new types. Unfortunately, when significant analgesic action appears, the ability to produce addiction is also demonstrable. There is one important exception which may, however, be the clue to a solution of the problem, analgesic action without addiction liability, which is the basis for all of the work on new analgesic agents.

A feature of the morphine structure is the occurrence in the molecule of an heterocyclic nitrogen carrying a methyl group, long believed to be optimal for analgesic action. Forty years ago, Pohl substituted allyl for this methyl group in codeine and reported that the resulting compound was to some extent antagonistic to morphine. ${ }^{18}$ In 1942, Weijlard and Erickson succeeded in making a similar substitution in morphine. ${ }^{19}$ This is the compound now known as nalorphine (Nalline). It is strongly antagonistic to many of the effects of morphine in suitable concentration; it will not satisfy a morphine addiction nor produce physical dependence when repeatedly administered. Its antagonistic effect is demonstrated strikingly by the removal of the respiratory depression produced by overdoses of morphine and morphine-like substances and by the precipitation of a typical abstinence syndrome if it is given to a morphine addict.

In the laboratory, nalorphine exhibits little analgesic action. It can be given to man in combination with morphine, at least in certain dose ratios, without interfering materially with morphine's analgesic effect. Most recently, it has been reported that nalorphine given alone to patients in pain is as effective as morphine in relieving that pain. ${ }^{20}$ Here, then, is one instance in which analgesia equivalent to that of morphine can be produced by a compound which is not addicting. Nalorphine is not a practical analgesic or a practical solution of the addiction problem because of the occurrence of quite remarkable side-effects, worse if the individual has received recently a dose of morphine. Perhaps, however, it is not too much to expect that a nalorphine-like compound will be found without its disagreeable side-effects, a useful nonaddicting analgesic.

In conclusion, we can agree with opinion expressed by the Drug Addiction Committee of the National Research Council that "all needs for morphine and related substances for symptomatic relief can be met by synthetics now known." ${ }^{21}$ This does not say that synthetics are superior to the natural alkaloids, though some may be. We have reached the point where we could make out with the synthetics in clinical practice if the need arose, and we may be on the brink of a practical analgesic without addiction liability.

\footnotetext{
${ }^{18}$ See Pohl, Über das N-Allylnorcodein, einen Antagonisten des Morphins, $17 \mathrm{ZTSCHR}$. EXPER. PATr. THERAP. 370 (19I4).

${ }^{10}$ See Weijlard and Erickson, N-Allylnormorphine, 64 J. Aмr. Chem. Soc'y, 869 (1942).

${ }^{20}$ See Lasagna and Beecher, The Analgesic Effectiveness of Nalorphine and Nalorphine-morphine Combinations in Man, II2 J. Pharmacos. 356 (1954); Keats and Telford, Nalorphine, a Potent Analgesic in Man, $x \mathrm{x}_{7}$ id. at 190 (1956).

21 Commitree on Drug Addiction and Narcotics, Minutes of Tenth Meeting, fune r952, in Butu. Drug AdDiction and Narcottcs 343 (1952).
} 